\title{
$\nabla$ Role of MRI in Assessment of Hip Joint Avascular Necrosis
}

IJCRR
ection: Healthcare
ISI Impact Factor
(2019-20): 1.628
Value (2019): 90.81
SJIF (2020) = 7.893
Cc) () ()
Copyright@IJCRR

\section{Supriya Chagdal', Ranjit Ambad ${ }^{2}$, Tejas Sadavarte ${ }^{3}$, Bhushan N. Lakhkar ${ }^{4}$}

'Assistant Professor, Department of Radio-Diagnosis, Datta Meghe Medical College, Nagpur-441110, India; 'Associate Professor, Department of Biochemistry, Datta Meghe Medical College, Nagpur-441110, India; ${ }^{A}$ Assistant Professor, Department of Radio-Diagnosis Datta Meghe Medical College, Nagpur-441110, India; 4 Professor Department of Radio-Diagnosis Jawaharlal Nehru Medical College, Datta Meghe Institute of Medical Sciences Sawangi (Megheo, Wardha-442001, India.

\section{ABSTRACT}

Introduction: A new chapter in the clinical approach to avascular necrosis has begun with the development of cross-sectional imaging techniques, particularly magnetic resonance imaging (MRI). MRI is currently useful in the diagnosis of multiple symptomatic and asymptomatic cases of hip joint avascular necrosis.

Aims \& Objectives: To study the role of magnetic resonance imaging in the assessment of hip joint avascular necrosis.

Methods: It was cross-sectional, hospital-based research carried out over one year in a tertiary care centre. A total of 68 hip pathology cases with OPD complaining of hip joint pain were subjected to MRI scans and all those participants consented.

Results: Avascular necrosis was shown to demonstrate 94 per cent sensitivity. MRI diagnosis was correctly matched with provisional diagnosis in 64 out of 68 cases, providing 94 per cent of sensitivity and the remaining 4 patients were normal.

Conclusion: MRI is the modality of choice in the diagnosis of hip joint avascular necrosis. In determining the degree of osseous \& chondral involvement, MRI is helpful. MRI sensitivity in diagnosing avascular necrosis is 94 per cent in the current study and is very effective in the staging of avascular necrosis.

Key Words: Avascular necrosis, Hip joint, pathology, Magnetic resonance imaging, OPD

\section{INTRODUCTION}

The hip joint is a large synovial joint that has to bear a lot of weight and its rigid ball and socket or nut form, as well as the solid ligaments and muscles around it, provide its stability. ${ }^{1,2}$ The acetabular-cartilage is horse-shoe-shaped with a central portion that does not articulate with the femoral head without cartilage coverage (fossa acetabuli). Fatty tissue and ligamentum-teres are imaged on MRI inside the fossa. Except for the insertion of the ligamentum-teres, the femoral head is fully coated with hyaline cartilage. ${ }^{3,4}$ Compared to other joints, the hip joint cartilage is thin with a maximum thickness ventro-cranially at the acetabulum and ventro-laterally at the femoral head. In adults and kids, hip pain has distinct etiologies. ${ }^{5,6}$ Hip pain in adults may be caused by intra-articular disorders such as avascular necrosis, arthritis, loose bodies, labral tears, peri-articular pathology such as tendinitis and bursitis, or by extra-articular conditions such as lumbar spine pain, Sacro-illiac articulations, and syndromes of nerve capture. In the general population, the incidence of hip pain is 10 per cent and increases with age. ${ }^{7,8}$ Pain is generally characterized by long-standing symptoms in the hip and groin area that often do not heal within 6-12 months. Hip and groin pain has been reported to occur regularly in athletes and adults. With its excellent soft tissue contrast and resolution, with no operator reliance and no ionizing radiation, magnetic resonance imaging (MRI) is the imaging tool of choice for assessing hip joint anomalies. ${ }^{9}$ MRI provides useful data such as stress-fractures, avascular-necrosis of hip joint on occult bony and cartilage injury. The femoral head is the most prevalent site for avascular necrosis and can affect young and old patients. The present research was therefore conducted to study the role of MRI in the assessment of hip joint pathologies. ${ }^{10,11}$

AIMS \& OBJECTIVES: To study the role of magnetic resonance imaging in assessment of hip joint avascular necrosis.

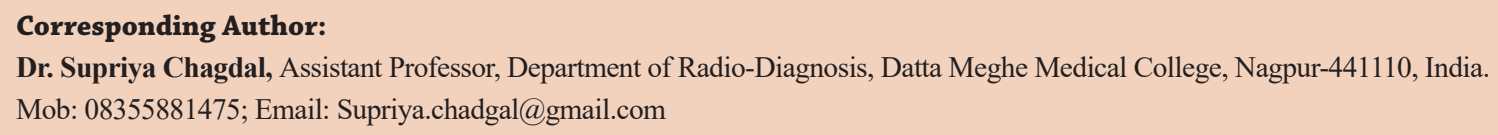




\section{MATERIALS AND METHODS}

The present research was a cross-sectional, hospital-based study to estimate the role of MRI in the early evaluation of hip joint avascular necrosis in tertiary health centres. The current period of research has been one year. For both indoor and outdoor patients with hip joint pain, the research population was referred to the Department of Radiology. The research population comprised a total sample size of 68 hip joint pain patients referred to the Department of Radiology at the hospital. Ethical committee clearance no DMIMS (DU) / IEC I 2020-21/9023.

\section{OBSERVATIONS AND RESULTS}

Table 1: Distribution as per age

\begin{tabular}{lc} 
Age group (years) & No of patients \\
$21-30$ & 16 \\
$31-40$ & 32 \\
$41-50$ & 20 \\
Total & 68 \\
\hline
\end{tabular}

Table 1 demonstrates the distribution of patients by age. It was found that the majority of patients were aged 31-40 years and 41-50 years, respectively. It was found that sore hip joints accompanied by low back pain were present in most patients. The other clinical presentation involves hip joint swelling with minimal movements and constitutional signs of hip pain. The majority of patients (64) had abnormal MRI findings in our sample, while 4 patients were normal.

\begin{tabular}{lc} 
Table 2: Distribution according to side involved \\
Side & No of patients \\
Right & 8 \\
Left & 16 \\
Bilateral & 40 \\
Total & 64 \\
\hline
\end{tabular}

Table 2 shows the distribution of patients according to the group concerned. It was noted that most of the bilateral side of the patient was affected (40), followed by the left side (16) and right side (8).

Table 3: Distribution according to Magnetic resonance imaging (MRI) findings in Avascular necrosis (AVN)

\begin{tabular}{lcc}
\hline MRI findings & No of patients $(\mathbf{n}=\mathbf{6 4})$ & Percentage \\
$\begin{array}{l}\text { Focal sub-chondral } \\
\text { signal abnormality }\end{array}$ & 64 & $100 \%$ \\
Double line sign & 48 & $75 \%$ \\
Marrow edema & 28 & $44 \%$ \\
Joint effusion & 24 & $38 \%$ \\
\hline
\end{tabular}

MRI results for avascular necrosis are shown in the table above. Most patients displayed focal sub-chondral signal abnormality (100 per cent) followed by double-line sign abnormality ( 100 per cent) ( 75 per cent). Marrow oedema (44 per cent) and joint effusion are the other findings ( 38 per cent) shown in table 3.

Table 4: Distribution according to Mitchelles classification of AVN

\begin{tabular}{lcc} 
AVN stages & No of patients & Percentage \\
\hline Stage A & 12 & $19 \%$ \\
Stage B & 16 & $25 \%$ \\
Stage C & 24 & $38 \%$ \\
Stage D & 12 & $18 \%$ \\
Total & 64 & $100 \%$ \\
\hline
\end{tabular}

By Michelle's classification, the above table 4 indicates MRI results in avascular necrosis. The majority of patients were found to have Stage C AVN (38 per cent), followed by Stage B (25 per cent).

Table 5: Distribution according to Ficat and Arlet classification of AVN

\begin{tabular}{lcc} 
AVN stages & No. of Patients & Percentage \\
Stage o & oo & oo $\%$ \\
Stage I & o8 & $13 \%$ \\
Stage II & 20 & $30 \%$ \\
Stage III & 28 & $44 \%$ \\
Stage IV & 08 & $13 \%$ \\
Total & 16 & $100 \%$ \\
\hline
\end{tabular}

Table 5 above shows MRI findings by Ficat and Arlet classification $^{5}$ in avascular necrosis. The majority of patients were found to have Stage III AVN (44 per cent), followed by Stage II ( 30 per cent $)$

Table 6: Distribution according to MRI diagnosis sensitivity of different lesions

\begin{tabular}{lccc}
$\begin{array}{l}\text { Provisional Diag- } \\
\text { nosis }\end{array}$ & No of patients & MRI +ve & Sensitivity \\
$\begin{array}{l}\text { Avascular Necrosis } \\
\text { (Total) }\end{array}$ & 68 & 64 & $94 \%$ \\
\hline
\end{tabular}

Above table 6 illustrates MRI sensitivity in the diagnosis of hip joint avascular necrosis. In the current study, 64 out of 68 cases correctly matched MRI diagnosis with provisional diagnosis, 94 per cent sensitivity, and 4 patients were normal. 


\section{DISCUSSION}

In being radiation-free, non-invasive, excellent soft-tissue contrast, multiplanar imaging capability, and high sensitivity in the detection of femoral head osteonecrosis, MRI has a distinct advantage over other modalities. We diagnosed a significant number of early AVN patients with radiographs. In patients with advanced-stage, AVN on the contralateral hip was normal and also observed. Therefore, MRI is the method of choice for AVN staging, which helps to treat patients early and reliably. In the current study, 64 out of 68 cases correctly matched MRI diagnosis with provisional diagnosis, 94 per cent sensitivity, and 4 patients were normal. In a study conducted by Hayam Abd et al ${ }^{2,5}$, avascular necrosis MRI sensitivity was 88 per cent. In the current analysis, it was found that the bilateral side of the patient was mainly affected (40), followed by the left side (16) and right side (8). Khaladkar $\mathrm{S}$ et al conducted a study to determine the diagnostic role of MRI in avascular necrosis patients and found that $44(61 \%)$ and 14 patients had bilateral side effects (61\%) and unilateral side effects (39 per cent). The avascular necrosis MRI findings among patients showed that most patients had focal subchondral signal abnormality $(100 \%)$, accompanied by double-line sign abnormality $(100 \%)(75 \%) .{ }^{12,13}$. Marrow oedema (44 per cent) and joint effusion are the other findings ( 38 per cent). These results are well associated with the Hayam Abd et $\mathrm{al}^{2}$ and Kalekar et al ${ }^{8}$, Chaudhari $\mathrm{N}$ et al ${ }^{11}$. studies. Avascular necrosis MRI results among patients classified by Mitchelles ${ }^{4}$ showed that the majority of patients had Stage C AVN (38\%) followed by Stage B (25\%) while by Ficat and Arlet classification ${ }^{5}$, the majority of patients had Stage III AVN (44\%) followed by Stage II (30\%).

\section{CONCLUSION}

MRI is the modality of choice in the diagnosis of hip joint avascular necrosis. MRI is useful in determining the level of involvement of osseous, chondral and soft tissue. MR imaging reliably reveals joint effusions, synovial proliferation, defects of the articular cartilage, subchondral bone, ligaments, muscles, and soft tissue juxta-articulars. In the current study, MRI sensitivity in the diagnosis of avascular necrosis is $94 \%$. MRI is very useful for avascular-necrosis staging. In depicting bone and soft tissue oedema, MRI is the sensitive modality.

\section{ACKNOWLEDGEMENT}

The author acknowledges the immense help received from the scholars whose articles are cited and included in references of this manuscript. The author is also grateful to authors/editors/ publishers of all those articles, journals and books from where the literature for this article has been reviewed and discussed.

\section{Conflict of Interest: Nil}

\section{Source of Funding: Nil}

\section{REFERENCES}

1. Christoph Z. Magnetic resonance imaging of hip joint cartilage and labrum', Orthopedic Reviews. 2011; 63 (2): 1-6.

2. Hayam A. The role of MRI in the evaluation of painful hip joint (MRI of the hip joint), Int J Med Imag. 2014: 2 (3): 77-82.

3. Cotton A. Acetabular Labrum: MRI in asymptomatic volunteers. J Comput Assist Tomog. 1998; 22:1-7.

4. Mitchell D. Femoral head avascular necrosis: correlation of MR imaging, radiographic staging, radionuclide imaging, and clinical findings. Radiol. 1987; 162:709-715.

5. Varma AD, Dhande R. MRI evaluation of the pattern of anterolateral ligament and posterolateral corner injury associated with anterior cruciate ligament tear with its clinical correlation. Eur J Mol Clin Med. 2020;7(2):1977-1982.

6. Panchbhai A, Bhowate R. MRI evaluation of the involvement of parotid and submandibular glands by tongue squamous cell carcinoma. Oral Oncol. 2020;102.

7. Ficat R. Necrosis of the femoral head. In: Hungerford DS, eds. Ischemia and necrosis of bone. Baltimore, Md: Williams and Wilkins. 1980; 171-182.

8. Kalekar T. Role of magnetic resonance imaging findings in the evaluation of painful hip joint. Int J Med Health Res. 2017; Volume 3; Issue 7:105-111.

9. Hayashi D. Magnetic resonance imaging of subchondral bone marrow lesions in association with osteoarthritis. Semin Arthritis Rhe. 2012; 42: 105-8.

10. Tripathi P. Hip Pathology Findings on magnetic resonance Imaging: A Study from Tertiary Care Institute. Int J Sci Stud. 2016;4(3):35-38.

11. Chaudhari N. Study of MRI features of avascular necrosis of femoral head and to study association of bone marrow oedema and hip joint effusion with avascular necrosis. Int J Health Sci Res. 2015; 5(2):116-122.

12. Vaidya SV, Aneesh MK, Mahajan SM, Dhongade HS. Radiological assessment of meniscal injuries of the knee on magnetic resonance imaging. Intern J Cur Res Rev. 2020;12(15):98-102.

13. Mohabey A, Gupta S, Gawande V, Saoji K. A study on the correlation of magnetic resonance imaging and arthroscopy in evaluation of anterior cruciate ligament injury in cases of acute traumatic haemarthrosis of the knee: A prospective study. Intern J Cur Res Rev. 2020;12(14 Special Issue):14-17. 